\title{
Will the Lameness Locator Replace the Equine Vet?
}

\author{
Maria Fernanda Sepulveda Caviedes* \\ Structure and Motion Laboratory, Royal Veterinary College, North Mymms, AL9 7TA, UK
}

Submission: December 14, 2018; Published: January 23, 2019

*Corresponding author: Maria Fernanda Sepulveda Caviedes, DVM MVetMed PhD MRCVS, Structure and Motion Laboratory, Royal Veterinary College, North Mymms, AL9 7TA, UK

\section{Abstract}

Lameness diagnosis in the horse can be subjective and difficult especially when mild. There are lameness locator machines that have been developed to reduce the possible bias that exists in lameness diagnosis, which are a great tool for the equine clinician, however they are far from being able to replace his or her expertise.

\section{The problem that we have Today}

Some equine veterinarians love lameness while others hate them... but all must deal with them sooner or later in their careers. Why is lameness diagnosis such a challenging area of our daily routine? Because lameness detection is as much a science as an art. Traditional lameness examinations involving physical examination, trotting up the horse in the straight or circle over different surfaces, with or without a rider and nerve/ joint blocking, is not exact [1]. Studies has shown that the more experienced the clinician, he or she is better at detecting it and that there is usual disagreement between veterinarians examining the same case $[2,3]$. Even the speed of trot can influence the outcome [4] and even widely used diagnostic methods, such as flexions tests, can also be variable between horse genders [5]. In summary, lameness detection can be subjective specially when the lameness is subtle [6].

The solution is a machine capable of detecting very small differences in vertical movement between contralateral limbs. These "lameness locators" have got IMUs sensors equipped with accelerometers and gyroscopes that are attached to the tack or horse with double sided tape or Velcro and feed data to a laptop [7-10]. In seconds, the machine measures the amount of vertical asymmetry in millimeters and show where the feet are landing with respect to a center point. These lameness locators are more effective at detecting subtle lameness than veterinarians. Lameness locators objectivize the lameness by indicating the lame limb and giving the lameness a number.

\section{The Advantages of using Such Machines are Clear}

The lameness locator is quite portable and fits in a small suitcase or rucksack, making it easier to use in the field. The sensors are easy to put in place and do not leave a mark after removing them. To obtain the best readings, the horse should be trotted by a competent handler in a straight line on a hard, even surface that allows for at least 25 strides or for the lameness to stabilize [11]. The lameness locator facilitates lameness diagnosis by a wider range of types of vets. These include new graduates who are not confident in their abilities yet [12], veterinarians who do not deal with equine lameness on a daily basis, for example, mixed practice vets who do more small/large animals with the odd equine patient thrown to his/her caseload; but also experienced equine veterinarians who deal regularly with lameness but want to confirm their findings.

Lameness locator readings are also useful when referring a case or having a consultation with a colleague, as it is known that agreement between clinicians can vary considerably specially if the lameness is mild [13]. When the lameness is objectively measured, it can be compared and its progression assessed on other occasions or by another veterinary clinic. The only requirement would be to be aware of the slight difference of reading between brands of lameness locators [14]. The lameness locator data can be incorporated into the lameness examination routine and even flexion tests can be performed and evaluated with it positively [15].

In my experience, every horse that is examined for any condition should be assessed, if possible, by a lameness locator on more than one occasion, to have a "gait signature" on record for that individual. This could be useful later when the patient does come back to the clinic with a lameness complaint. The veterinarian will have to take into consideration the natural day to day, week to week variations of gait in horses [16]. Another potential use of the lameness locator would be to monitor rehabilitation of conditions that need increasing amounts 
of controlled exercise, for example horses recovering from tendonitis. Where a small increase in asymmetry could indicate that a reduction in exercise level is needed.

\section{Limitation of the Lameness Locator}

The machine can only give an indication of which limb is lame, giving a measure of asymmetry but cannot tell which anatomical part of the limb itself is painful or responsible for causing the lameness. Here the knowledge and diagnostic abilities of the veterinarian are vital: with diagnostic analgesia, used to pinpoint source of pain, and usual imaging such as ultrasonography, radiography and MRI being used to give more insight to the investigation. Recently data from the withers measured by the lameness locator has proven useful in the diagnosis of complicated, multi-limb lameness [17]. The veterinarians using the lameness locator have to take into consideration that certain surfaces reduce asymmetries more than others [18,19]; that different breeds of horses/disciplines allow for more asymmetry (higher threshold) than others, so measurements have to be interpreted with care until these thresholds have been established.

\section{The Final Message}

The take home message is that the lameness locator cannot replace the equine veterinarian yet but should be used routinely in every horse that is seen for lameness. It is another invaluable tool for lameness diagnosis in the arsenal available to the clinician. Ideally every horse should have a record of its "gait signature" while sound. Finally, it is the equine veterinarian, thanks to his or her knowledge, training and experience, who has to make the final decision on the numbers shown by the locator if they are a lameness or just an asymmetry [20].

\section{Acknowledgement}

Many thanks for all the support given by Dr Thilo Pfau and Prof Renate Weller from the Structure and Motion Laboratory at the RVC; to Dr Amy Barstow, to the trainers and staff of the Singapore Turf Club, special Dr Koos van der Berg for all their help.

\section{References}

1. Hammarberg M, Egenvall A, Rhodin M (2014) Subjective Evaluation of Lameness in Horses During Lungeing. Equine Vet J 46(S46): 41-41.

2. Parkes RSV, Weller R, Growth AM, May S, Pfau T (2009) Evidence of the development of 'domain-restricted' expertise in the recognition of asymmetric motion characteristics of hindlimb lameness in the horse. Equine Vet J 41(2): 112-117.

3. Hammarberg M, Egenvall A, Pfau T, Rhodin M (2016) Rater agreement of visual lameness assessment in horses during lungeing. Equine Vet $\mathrm{J}$ 48(1): 78-82.
4. Starke SD, Raistrick KJ, May SA, Pfau T (2013) The effect of trotting speed on the evaluation of subtle lameness in horses. Vet J 197(2): 245252.

5. Busschers E, van Weeren PR (2001) Use of the flexion test of the distal forelimb in the sound horse: repeatability and effect of age, gender, weight, height and fetlock joint range of motion. J Vet Med a Physiol Pathol Clin Med 48(7): 413-427.

6. Keegan KG, Yonezawa Y, Maki H, Pai PF, Dent EV, et al. (2011) Assessment of repeatability of a wireless, inertial sensor-based lameness evaluation system for horses. AJVR 72(9): 1156-1163.

7. Keegan KG, Yonezawa Y, Pai PF (2004) Sensor based system of equine motion analysis for the detection and quantification of forelimb and hindlimb lameness in horses. AJVR 65: 665-670.

8. Warner SM, Koch TO, Pfau T (2010) Inertial sensors for assessment of back movement in horses during locomotion over ground. Equine Vet J 42: 417-424.

9. McCracken MJ, Kramer J, Keegan KG, Lopes M, Wilson DA, et al. (2012) Comparison of an inertial sensor system of lameness quantification with subjective lameness evaluation. Equine Vet J 44(6): 652-656.

10. Starke S, May S, Pfau T (2014) Towards Reliable Objective Lameness Quantification on the Circle. Equine Vet J 46(S46): 48-48.

11. Hopkins S, Pfau T (2014) Effect of Side of Handling on Movement Symmetry in Horses. Equine Vet J 46: 42.

12. Starke SD, Pfau T, May SA (2014) How do Students Approach Lameness? A Case Study. Equine Vet J 46(S47): 18-19.

13. Keegan KG, Dent EV, Wilson DA, Janicek J, Kramer J, et al. (2010) Repeatability of subjective evaluation of lameness in horses. Equine Vet J 42(2): 92-97.

14. Pfau T, Boultbee H, Davis H, Walker A, Rhodin M (2016) Agreement between two inertial sensor gait analysis systems for lameness examinations in horses. Equine Vet Edu 28(4): 203-208.

15. Marshall JF, Lund DG, Voute LC (2012) Use of a wireless, inertial sensorbased system to objectively evaluate flexion tests in the horse. Equine Vet J 44(S43): 8-11.

16. Sepulveda Caviedes MF, Forbes BS, Pfau T (2018) Repeatability of gait analysis measurements in Thoroughbreds in training. Equine Vet J 50(4): 513-518.

17. Pfau T, Noordwijk K, Sepulveda Caviedes MF, Persson-Sjodin E, Barstow A, et al. (2018) Head, withers and pelvic movement asymmetry and their relative timing in trot in racing Thoroughbreds in training. Equine Vet J 50(1): 117-124.

18. Cheetham LT, Forbes BS, McCarthy R, Pfau T, Sepulveda Caviedes MF (2018) Effect of surface type on head and trunk movement asymmetry in racing Thoroughbreds during in-hand trot-ups. Equine Vet J 50(S52): 18-18.

19. Burden ER, Pfau T, Witte TH (2013) Objective Assessment of Gait Asymmetry in Polo Ponies. Equine Vet J 45(S44): 9.

20. Weeren PR, Pfau T, Rhodin M, Roepstorff L, Serra Bragança F, et al. (2017) Do we have to redefine lameness in the era of quantitative gait analysis? Equine Vet J 49(5): 567-569. 
